\title{
Physico-Chemical and Mechanical Characteristics of Super plasticized composite Cements Containing High Replacement Siliceous Fly Ash M.Heikal $^{1,2}$, A.I.Ali ${ }^{1}$, M.N.Ismail ${ }^{3}$ and B.S.Ibrahim ${ }^{1}$ \\ ${ }^{1}$ Chemistry Dept., Faculty of Science, Benha Univ., Benha, Egypt \\ ${ }^{2}$ College of Science, Al Imam Mohammad Ibn Saud, Islamic Univ., ( IMSIU ), P.O.Box 90950, Riyadh, Saudi Arabia \\ ${ }^{3}$ Polymer and Pigment Dept., National Research Center, Dokki, Cairo, Egypt E-Mail: Mohamed.heikal@fsc.bu.edu.eg
}

\begin{abstract}
This work aims to study the effect of partial substitution of ordinary Portland cement (OPC) by fly ash (FA) on the physico-chemical and mechanical properties of the hardened on the properties of composite cement pastes (CCP). The effect of FA content was studied by the determining chemically combined water, free lime contents, total porosity, gel/space ratio, bulk density and compressive strength on the hydration progressing up to 90 days. The free lime of pozzolanic cement pastes increases up to 7 days, and then decrease up to 90 days, due to pozzolanic reaction of FA. It was found that, the increase of FA content in FA-CCP decreases the required water of standard consistency values and increases the setting times. The partial substitution of OPC with FA leads to higher porosity values, leads to decrease the compressive strength values in comparison with OPC control pastes. The lower values of free lime contents were obtained for SF-CCP with the formation of further additional amounts of C-S-H, C-A-H and C-A-S-H as a result of the pozzolanic reaction. The hydrated products formed mainly fibril C-S-H. FA show a dense microstructure rim of the inner hydrated product at the surface of reacted and unreacted FA particles.
\end{abstract}

Keywords: Fly ash, composite cement, compressive strength, gel/space ratio, microstructure

\section{Introduction}

Large quantities of industrial by-products are produced every year by chemical and agricultural industries. These materials have dual problem on the environmental and health hazards. Hence there are environmental problems associated with the disposal of mineral by-products, such as FA, lime sludge, phosphogypsum and others. The development and use of blended cement is growing rapidly in the construction industry mainly due to considerations of cost saving, energy saving, environmental protection and conservation of resources[1].FA is a heterogeneous material, which is characterized by a high variance of particles in terms of chemical composition, crystallinity and porosity, obtained from different thermal power stations is now being considered as a cementitious ingredient for concrete.FAis finely divided waste by-product precipitated electrostatically from the combustion of pulverized coal in boilers at the thermal power plants. FA particles are spherical and have the same fineness as cement so that the silica is readily available for reaction [2,3].The properties of FA are variable and depend upon several factors, such as the type and origin of coal, degree of coal pulverization, flame temperature, oxidation condition and pretreatment during or prior to burning for $\mathrm{SO}_{\mathrm{x}}$ removal, method of collection, storage of FA and carbon content $[4,5]$.The use of FA in mortar and concrete, as a partial replacement of OPC, appears to constitute a very satisfactory outlet for this industrial by-product and significant savings in the cost of production of concrete. To get full resemblance in properties with OPC, FAneeds special treatments like mechanical grinding, thermal activation, alkali activation etc[6,7].

FA is a polyfunctional ingredient in concrete $[8,9]$. It performs the following functions in concrete; aggregate, active mineral admixture, plasticizer, and micro-filler. Significance of these functions depends on FA properties and its application. The pozzolanic activity of FA is defined in terms of the reactions of the reactions of its main components; $\mathrm{SiO}_{2}$ and $\mathrm{Al}_{2} \mathrm{O}_{3}$ with $\mathrm{Ca}(\mathrm{OH})_{2}(\mathrm{CH})$ to form C-S-H and $\mathrm{C}-\mathrm{A}-\mathrm{H}$ phases [10].The hydration of four mixes of fly ashlime 90:10, 80:20, 70:30 and 60:40 mass\% was studied. Free lime, insoluble residue and combined water contents were determined up to 90 days. The results revealed that the combined water content increases with the lime content especially after 7 days up to 90 days. DTA illustrates the formation of C-S-H, C-A-H and C-A-S-H hydrates. FA has a slightly pozzolanic activity and may be used in low cost filled-pozzolanic cements [11,12]. The effect of partial substitution of SRC or OPC with 10, 20 and 30 mass\% FA on the properties of FA-pozzolanic cement pastes was investigated [13]. The early hydration reaction was studied using electrical conductivity to monitoring the change occurring during the setting and hardening. The increase of FA content leads to decrease the compressive strength and increase the total porosity in comparison with SRC and OPC control pastes [13].

Effect of partially replacement of FA up to fully by limestone dust was studied. The results show that the substitution of FA by 5-10 mass\% limestone with SRC pastes decreases the electrical conductivity. Increase of limestone content (15 and 20 mass\%), the 
electrical conductivity increases than sample free from limestone. 5 mass $\%$ limestone extended the final setting times. On the other side, the increase of limestone content, the final setting times are shortened. The combined water, degree of hydration and the gel/space ratio increase with limestone content. The free lime contents increase at 7 days, then decreases up to 90 days. On the other hand, the compressive strength and total porosity decrease with limestone content [14].

The hydration and durability of FA-limestonepozzolanic cement were studied. The results revealed that the increase of limestone content the water of consistency of cement pastes increases, whereas, the initial and final setting time are reduced. The increase of the limestone up to $10-20 \%$, the free lime content decreases up to 90 days, on the other hand, free lime content of $30 \%$ limestone increases up to 90 days. Cement pastes containing FA only show lower values of total sulphate and chloride contents than SRC pastes. The compressive strength of $20 \% \mathrm{FA}$ and $10 \%$ limestone showed the higher compressive strength than the other cements when immersed in tap and Caron's Lake water, show lower values of total sulphate, due to decreased accessibility of sulphate ions towards the dense structure with low capillary pore [15].

The aim of the present work is to study the effect of FA on physico-chemical and mechanical properties of CCP up to 90 days.

\section{Materials and methods \\ 2.1 Materials \\ 2.1.1Cement}

The cement used in this study was ASTM Type (I) ordinary Portland cement (OPC) provided from Lafarge Cement Company, Egypt. The Blaine surface area of OPC was $3000 \pm 50 \mathrm{~cm}^{2} / \mathrm{g}$. The chemical analysis of OPC is given in Table (1)

\subsubsection{Fly ash ( FA )}

Fly ash (FA) was supplied from Sika Chemical Company, Egypt. The specific surface area of FA was $3774 \mathrm{~cm}^{2} / \mathrm{g}$. The chemical analysis of FA is given in Table (1) Fig $(1,2)$ represented the XRD patterns and SEM of FA.Fig. FA consists of spherical vitreous particles of different sizes in the range $<50$ $\mu \mathrm{m}$, hollow and spheres.

\subsubsection{Superplasticizer}

Superplasticizer (SP) based on polycarboxylate was obtained from Sika Company, El-Abor City, Egypt. Table (2) shows some physical and chemical properties of polycarboxylate admixture used in this study.

\subsection{Methods of investigation}

The mix compositions of the prepared cement blends are given in Table (3) The required water of standard consistency and setting times were measured according to ASTM specification [16].At the end of mixing, the paste was directly moulded in $(2 \times 2 \times 2 \mathrm{~cm})$ stainless steel moulds. Immediately after molding, the specimens were cured in a humidity chamber at $100 \% \mathrm{RH}$ at a constant temperature $25 \pm 1^{\circ} \mathrm{C}$ for the first 24 hours and then immersed in tap water until the time of testing $(1,3,7,28$ and 90 days). The hydration of cement pastes was stopped by pulverizing $10 \mathrm{~g}$ of representative sample in a beaker containing 1:1 (v/v) methanol-acetone mixture, and then mechanically stirred for $1 \mathrm{~h}$. The mixture was filtered through sintered glass $\mathrm{G}_{4}$, after washing two times with the stopping solution and diethyl ether, then dried at $70^{\circ} \mathrm{C}$ for $1 \mathrm{~h}$, then collected in polyethylene bags; sealed and stored in desiccators for analysis [17].

The combined water content is considered as the percent of ignition loss of the dried sample (on the ignited weight basis). Approximately $2 \mathrm{~g}$ of the predried samples were ignited up to $1000^{\circ} \mathrm{C}$ for $1 \mathrm{~h}$ soaking time. The results of combined water contents were corrected for the water of free portlandite present in each sample [18]. Free lime contents of the hydrated cement pastes can be thermally determined. $0.5 \mathrm{~g}$ sample of the hardened cement was placed in a porcelain crucible introduced into a cold muffle furnace (room temperature). The temperature was increased up to 390 then to $550^{\circ} \mathrm{C}$ at heating rate of $3^{\circ} \mathrm{C} / \mathrm{min}$. The loss of weight occurred between 390 and $550^{\circ} \mathrm{C}$ with soaking time of $15 \mathrm{~min}$ is equal to the weight of water of calcium hydroxide. Therefore, the free portlandite can be calculated [18].

Bulk density was measured before the specimens subjected to compressive strength determination. Each measurement was conducted on at least three similar cubes of the same mix composition and curing time [15]. Compressive strength was determined according to (ASTM Designation: C-150, 2007)[19]. A set of three cubes was tested using compressive strength machine of SEIDNER, Riedinger, Germany, with maximum capacity of $2000 \mathrm{kN}$ force.

The crystalline phases of cement pastes were identified using XRD technique of BRUXER, Axs D8 ADVANCE A8, and GERMANY Diffractometer. The samples were finely ground to pass a 200-mesh sieve. The identification of all samples was confirmed by computer-aided search of the PDF database obtained from the Joint Committee on Powder Diffraction Standards-International Center for Diffraction Data (JCPDA-ICDD), 2001.

Thermal gravimetric analysis (TGA) was carried out using DTA-50 Thermal Analyzer (Schimadzu Co., Tokyo, Japan). A dried sample of about $50 \mathrm{mg}$ $(-53 \mu \mathrm{m})$ was used at heating rate $20^{\circ} \mathrm{C} / \mathrm{min}$ under nitrogen atmosphere. 
3. Results and discussion

3.1 Hydration behavior of composite cement pastes

\subsubsection{Water of standard consistency and setting} times

The variations of the required water of standard consistency and setting times of OPC and FA-CCP containing 10, 25 and 50 mass $\%$ FA with and without SP are given in Table (3) The results show that FA-CCP blends require higher water demands as well as elongated final setting times in the comparison with OPC pastes, this is due to the relatively low rate of hydration of FA as related to its mineralogical composition. The low hydraulic properties of fly ash are due to that it constitutes mainly of crystalline phases such as quartz, mullite and hematite [11-15].The retardation of setting process, may be due to the decrease of OPC portion in comparison with FA-CCP pastes [20,21]. FAcomposite cement paste containing 10 mass\% FA tends to shorten the initial setting time than the plain cement paste (OPC). This is principally due to the nucleating effect, which accelerates the rate of cement hydration. As the amount of FA increases up to 50 mass $\%$, the initial setting time elongated. This is mainly due to the dilution effect of the cement, which decreases the rate of hydration of FAcomposite cement pastes in comparison with OPC. The required water of standard consistency decreases in thepresence of SP as shown in Table (3) This is due to the increase of fluidity of the cement pastes leading to reduction in required water of standard consistency [22]. In the presence of SP, the final setting time of FA-CCP pastes elongated with FA content.

\subsubsection{Compressive strength}

Compressive strength of OPC and FA-composite cement pastes in the presence and absence of SP cured up to 90 graphically plotted in Fig (3) The values of the compressive strength increase with curing time for all hydrated cement paste, this is due to the continuous hydration and formation of excessive amounts of hydrated (C-S-H, C-A-H and $\mathrm{C}-\mathrm{A}-\mathrm{S}-\mathrm{H})$. These hydrated products deposited in the available open pores forming a closed compact structure. On the other hand, the compressive strength of cement pastes decreases with FA content as shown in Fig (3A,3B) [23-26]. This is due to lower activity of the FA particles as well as due to the decrease of cement content, which affects the mechanical properties of the hardened cement pastes [27].This reduction in the compressive strength of FA-CCP pastes is proportional to the content of FA, which affects the mechanical properties of the hardened cement pastes [28]. Also, the compressive strength results are in a good agreement with those of total porosity, bulk density as well as combined water contents. The strength development depends primarily on the formation of hydrated calcium silicate as the main hydration product, which is precipitated into the water filled spaces to form a more compact body. This is mainly attributed to crystallization of the initially formed hydrates, having strong binding forces and/or their transformation into other hydration products having weaker binding forces [29].

The compressive strength of FA-composite cement pastes increase in the presence of SP as shown in Fig (3B) The required water of standard consistency as well as initial porosity decreases in the presence of SP. The decrease in the total porosity facilitates the approaching of active silica and alumina containing FA from the liberated lime from the hydration of cement phases $\left(\mathrm{C}_{3} \mathrm{~S}\right.$ and $\left.\beta-\mathrm{C}_{2} \mathrm{~S}\right)$ to form additional amounts of C-S-H, C-A-H and C-A$\mathrm{S}-\mathrm{H}$ with low lime content, leading to relatively homogeneous composites. At later ages (90 days), FA-CCP paste containing 10\% FA gives the highest values of compressive strength than those of the other FA-CCP pastes; this is due to the efficiency of the pozzolanic reaction of $\mathrm{FA}$ with $\mathrm{CH}$ liberated from the hydration of $\mathrm{C}_{3} \mathrm{~S}$ and $\beta-\mathrm{C}_{2} \mathrm{~S}$.

\subsubsection{Total porosity and bulk density}

The total porosity and bulk density of OPC and FA-CCP pastes cured for 1, 3, 7, 28 and 90 days are graphically presented in Fig (4) The total porosity for all cement pastes decreases with curing time, whereas the bulk density increases. The values of the bulk density increase with curing time for all hydrated FA-CCP pastes; this is due to the continuous hydration and formation of excessive amounts of hydrated products (C-S-H, C-A-H and CA-S-H). The bulk density decreases with the increase of FA content. The results of bulk density for cement pastes in the presence of SP are higher than those without SP, this mainly due to the decrease of mixing water which increases the mechanical properties as shown in Fig (4B) The total porosity of FAcomposite cement pastes becomes closer; this is attributed to the predominance of the pozzolanic reaction, especially at the later hydration ages (90 days). Mix AS1 (10 mass\% FA) has a lower values of total porosity than those of FA-CCP pastes. This behavior is more pronounced for FA-CCP paste containing $10 \% \mathrm{FA}$, where lower values of the total porosity at the later hydration ages. In addition, the total porosity values of the hardened FA-CCP paste containing $10 \% \mathrm{FA}$ in the presence of SP are relatively lower than those of the other pastes at all curing ages. This is mainly due to the decrease of the $\mathrm{W} / \mathrm{C}$ ratio (initial porosity) as well as the filler effect of FA.

\subsubsection{Free lime contents}

The free lime contents of OPC and FA-composite cement pastes cured up to 90 days are graphically represented in Fig (5) Evidently, the free lime content of OPC paste increases with curing age up to 90 
days. The increase of the free lime contents is due to the continuous hydration of the main cement phases $\left(\mathrm{C}_{3} \mathrm{~S}\right.$ and $\left.\beta-\mathrm{C}_{2} \mathrm{~S}\right)$, liberating $\mathrm{CH}$. As FA content increases the values of free lime decrease. The initial increase of free lime in FA-CCP pastes is mainly due to the progressive hydration of calcium silicate phases $\left(C_{3} S\right.$ and $\left.\beta-C_{2} S\right)$. The decrease of free lime contents is due to the pozzolanic reaction of FA. There are two different processes; one tending to increase $\mathrm{CH}$ content and the another tending to decrease it $[13,30]$. At 1-7 days the rate of liberation of $\mathrm{CH}$ exceeds the rate of lime consumption. After 790 days the rate of consumption is higher than its liberation. Therefore, $\mathrm{CH}$ contents decrease with curing time up to 90 days. Free lime contents of superplasticized FA-CCP pastes show a lower free lime values than those of specimens without superplasticizer up to 90 days as shown in Fig (5B)

\subsubsection{Chemically combined water contents}

Fig (6) represents the variations of the chemically combined water contents of OPC and FA-CCP pastes with and without SP. The chemically combined water content increases gradually with curing time for all hardened cement pastes, leading to the formation of more excessive amounts of hydrated products, which precipitated in the available open pores system of the hardened cement pastes. The increase of FA content decreases the chemically combined water contents [31,32]. Therefore, FA shows somewhat pozzolanic activity, which decrease the hydration characteristic of FA-CCP pastes $[33,34]$. The combined water content of FA-CCP pastes decrease. The chemically combined water contents of superplasticizedFA-CCP pastes were decreased than those of unsuperplasticized pastes as shown in Fig (6B) this is attributed to the decrease of required water of standard consistency.

\subsubsection{Gel space ratio}

The gel/space ratios (X) of the hydrated OPC and FA-composite cement pastes were calculated on the basis of the degrees of hydration and their W/C ratios. The strength of the pastes is affected by W/C ratio, degree of hydration, air content, cement additives and temperature [35-37]. On increasing the amount of hydration products the gel/space ratio, consequently increases as shown in Fig (7) The strength can be correctly related to the solid hydration products and to the space available for formation of these products. The synergistic effect of hydration products formed in the pores of the cement pastes enhances the compressive strength. The results show that the gel/space ratio increases with curing time for all cement pastes. This is due to the progress of hydration products to increase of the amounts of $\mathrm{C}-\mathrm{S}-\mathrm{H}, \mathrm{C}-\mathrm{A}-\mathrm{H}$ and $\mathrm{C}-\mathrm{A}-\mathrm{S}-\mathrm{H}$ hydrated gel increasing of gel/space ratio. The presence of 1 mass $\% \mathrm{SP}$, the gel/space ratio increases, this is due to the formation of dense and close-textured structure. The gel/space ratios of A1 and AS1 mixes show an increase than those of OPC and other FA-CCP pastes in the absence and presence of polycarboxylate SP as shown in Fig (7A,7B) This is due to A1 and AS1 mixes act as nucleating sites to improve the hydrated products.

\subsubsection{XRD diffraction patterns}

X-ray diffractgrams of the mixes A3 and AS3 hydrated for 90 days are shown in Fig (8) shows the formation of $\mathrm{C}-\mathrm{S}-\mathrm{H}$ and $\mathrm{CH}$ phases as the main hydration products. The peaks characterizing the anhydrous cement phases $\left(\beta-\mathrm{C}_{2} \mathrm{~S}, \mathrm{C}_{3} \mathrm{~S}\right)$, quartz and $\mathrm{CaCO}_{3}(\boldsymbol{C} \overline{\boldsymbol{C}})$ appeared in the XRD diffraction patterns. The intensities of the peaks characterizing to anhydrous cement phases decrease with curing time, whereas, the intensities of the hydrated products peaks increase with increasing age of hydration. The peak characteristic to C-S-H overlapped with $\boldsymbol{C} \overline{\boldsymbol{C}}_{\text {increases with age of hydration; }}$ this is due to progress of hydration up to 90 days, this peak could also be detected in the diffraction patterns at $3.03 \AA$. The peak characteristic to C-S-H increases, where the peaks of $\mathrm{CH}$ decrease markedly with curing time, this is mainly due to the enhanced rate of pozzolanic interaction of FA with the liberated $\mathrm{CH}$, forming additional amount of C-S-H. Mix AS3 exhibits lower intensity of $\mathrm{CH}$ and higher intensity of diffraction lines characteristic to $\mathrm{C}-\mathrm{S}-\mathrm{H}$ peaks in comparison with those of mix A.3 free from superplasticizer.

\subsubsection{Differential thermal analysis}

Fig (9A,9B) illustrate DTA/TGA thermograms of hydrated mixes A3 and AS3. The weight losses at $1000^{\circ} \mathrm{C}$ were found to be $9.71,12.00$ and $15.23 \%$ for A3 mix, where for AS3 mix were 8.02, 10.95 and 13.78 hydrated for 1,7 and 90 days respectively. DTA/TGA thermograms show the presence of three main endothermic peaks and one exothermic peak. The first peak located at $100-120^{\circ} \mathrm{C}$, corresponding to the decomposition of C-S-H, C-A-H and C-A-S-H hydrated products. The decomposition of $\mathrm{C}-\mathrm{S}-\mathrm{H}$ peak overlapped with the decomposition of calcium sulphoaluminate hydrates (ettringite and monosulfate hydrates) as well calcium alumino-silicate hydrates peaks [14]. The second peak at $450-500^{\circ} \mathrm{C}$, is attributed to decomposition of $\mathrm{Ca}(\mathrm{OH})_{2}$ [38]. The third endothermic peak was observed at $750-785^{\circ} \mathrm{C}$, which is due to the decomposition of calcium carbonate. The exothermic peak located at $850-890^{\circ} \mathrm{C}$ is attributed to the crystallization of the pseudowollastonite phase (monocalcium silicate, CS). This exothermic peak is characteristic for the decomposition of C-S-H $[39,40]$.

The main features of the thermograms are characterized by an increase in the peak area of $\mathrm{C}-\mathrm{S}$ $\mathrm{H}, \mathrm{C}-\mathrm{A}-\mathrm{H}$ and $\mathrm{C}-\mathrm{A}-\mathrm{S}-\mathrm{H}$ with curing time due to continuous hydration of the cement pastes. The 
M.Heikal, A.I. Ali1, M.N. Ismail, B.S. Ibrahim

losses of endothermic peak below $200^{\circ} \mathrm{C}$ were found to be $3.09,4.89$ and $8.45 \%$ for A3 mix, while for AS3 mix were 2.67, 4.57 and 7.30 for specimens hydrated for 1,7 and 90 days respectively, which corresponding to the decomposition of C-S-H, C-A$\mathrm{H}$ and $\mathrm{C}-\mathrm{A}-\mathrm{S}-\mathrm{H}$ hydrated products. The intensity of $\mathrm{C}-\mathrm{S}-\mathrm{H}$ peaks increases with curing time. From the endothermic peak located at $450-500^{\circ} \mathrm{C}$, it is clear that the peak area increases from 1 day up to 7 days, then decreases at 90 days, this is due to the pozzolanic reaction of FA with liberated lime. As the curing time increases the exothermic peak located at $850-890^{\circ} \mathrm{C}$, shows an increase in the areas and intensities of the crystallization of the pseudowollastonite phase from 1 day up to 90 days.

The results showed also that the weight loss decrease in the presence of SP and increase in the absence of SP as shown in Fig (9A,9B)This exothermic peak is characteristic of the decomposition of the hydrated calcium silicate hydrated produced as a result of the pozzolanic reaction between $\mathrm{FA}$ and the free $\mathrm{CH}$ liberated during OPC hydration.

\subsubsection{Microstructure}

Fig (10) shows SEM micrograph of mix AS3 hydrated at 1 and 90 days. SEM micrograph shows a layer of surface hydrated products was found around FA particles after 1 day Fig (10A) These hydrated products are mainly amorphous ill-crystals of C-S-H. FA particles form also, inner hydration products [41]. After 90 days, the hydrated products formed mainly fibril $\mathrm{C}-\mathrm{S}-\mathrm{H}$ and dense crystalline hydrated products. FA particles partially and fully hydrated show a dense microstructure rim of the inner hydrated product, which was observed between the dense layer of hydration products at the surface of reacted and unreacted FA particles Fig (10B) [42].

Table (1) Chemical analysis of OPC, FA (mass, \%).

\begin{tabular}{llllllllll}
\hline & $\mathbf{S i O}_{\mathbf{2}}$ & $\mathbf{F O}_{\mathbf{3}}$ & $\mathbf{A l}_{\mathbf{2}} \mathbf{O}_{\mathbf{3}}$ & $\mathbf{C a O}$ & $\mathbf{M g O}$ & $\mathbf{S O}_{\mathbf{3}}$ & $\mathbf{K}_{\mathbf{2}} \mathbf{O}$ & $\mathbf{N a}_{\mathbf{2}} \mathbf{O}$ & L.O.I \\
\hline OPC & 19.3 & 3.8 & 3.94 & 62.67 & 1.90 & 3.22 & 0.44 & 0.22 & 3.04 \\
$\mathrm{FA}$ & 63.10 & 5.40 & 26.54 & 2.33 & 0.00 & 0.09 & 0.85 & 0.52 & 0.80 \\
\hline
\end{tabular}

Table (2) Physical and chemical properties of polycarboxylatesuperplasticizer.

\begin{tabular}{ll}
\hline Appearance & Light brownish liquid \\
Solid residue $\%$ & approximately $36 \%$ \\
pH & $5.2-5.3$ \\
Specific gravity (kg/l) & approximately $1.06 \%$ \\
Rotational viscosity (MPa) & 79.30 \\
Carbon-content (C\%) & 52.25 \\
\hline
\end{tabular}

Table (3) Mix compositions of OPC-FA-CCPblends, consistency and setting times of the prepared composite cements.

\begin{tabular}{lllllll}
\hline Mix No. & OPC, $\%$ & FA, $\%$ & SP, $\%$ & Consistency, \% & \multicolumn{2}{c}{ Setting times (min) } \\
\cline { 5 - 7 } & & & & & Initial set & Final set \\
\hline A.0 & 100 & 0 & 0 & 26.5 & 165 & 275 \\
A.1 & 90 & 10 & 0 & 26.0 & 116 & 265 \\
A.2 & 75 & 25 & 0 & 28.0 & 120 & 300 \\
A.3 & 50 & 50 & 0 & 29.0 & 120 & 360 \\
AS0 & 100 & 0 & 1 & 20.1 & 65 & 220 \\
AS 1 & 90 & 10 & 1 & 20.9 & 90 & 240 \\
AS2 & 75 & 25 & 1 & 21.2 & 110 & 260 \\
AS3 & 50 & 50 & 1 & 21.9 & & 275 \\
\hline
\end{tabular}




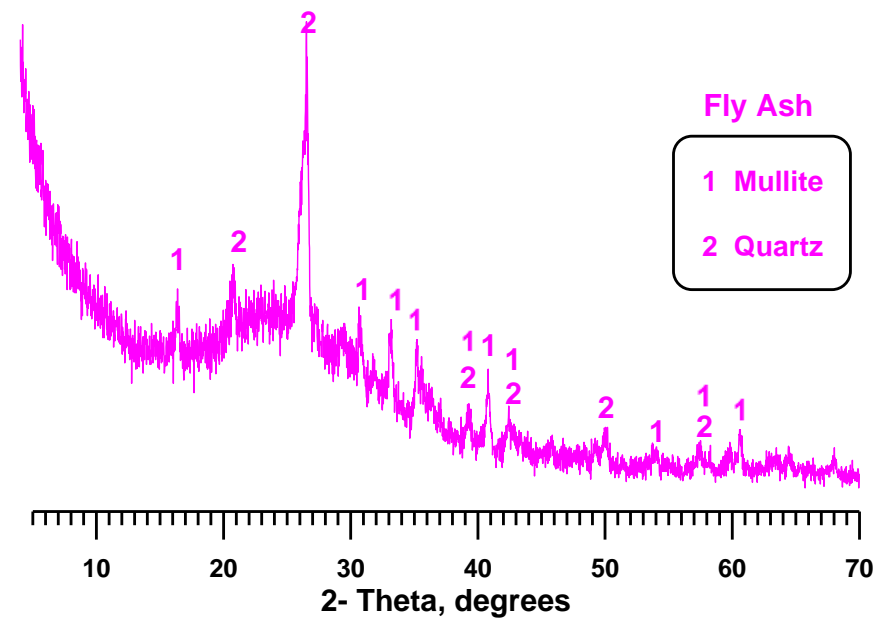

Fig (1) XRD pattern of FA

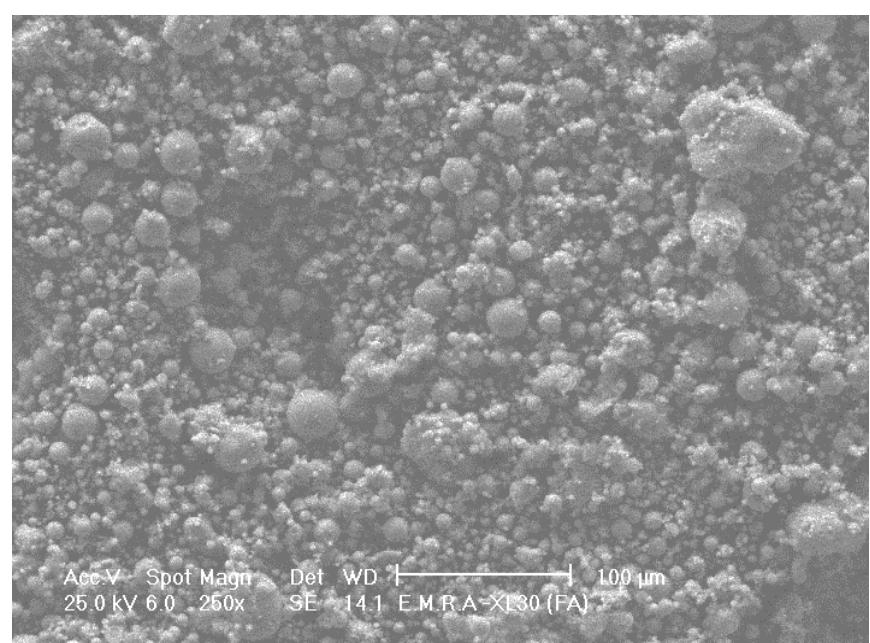

Fig (2) SEM of FA

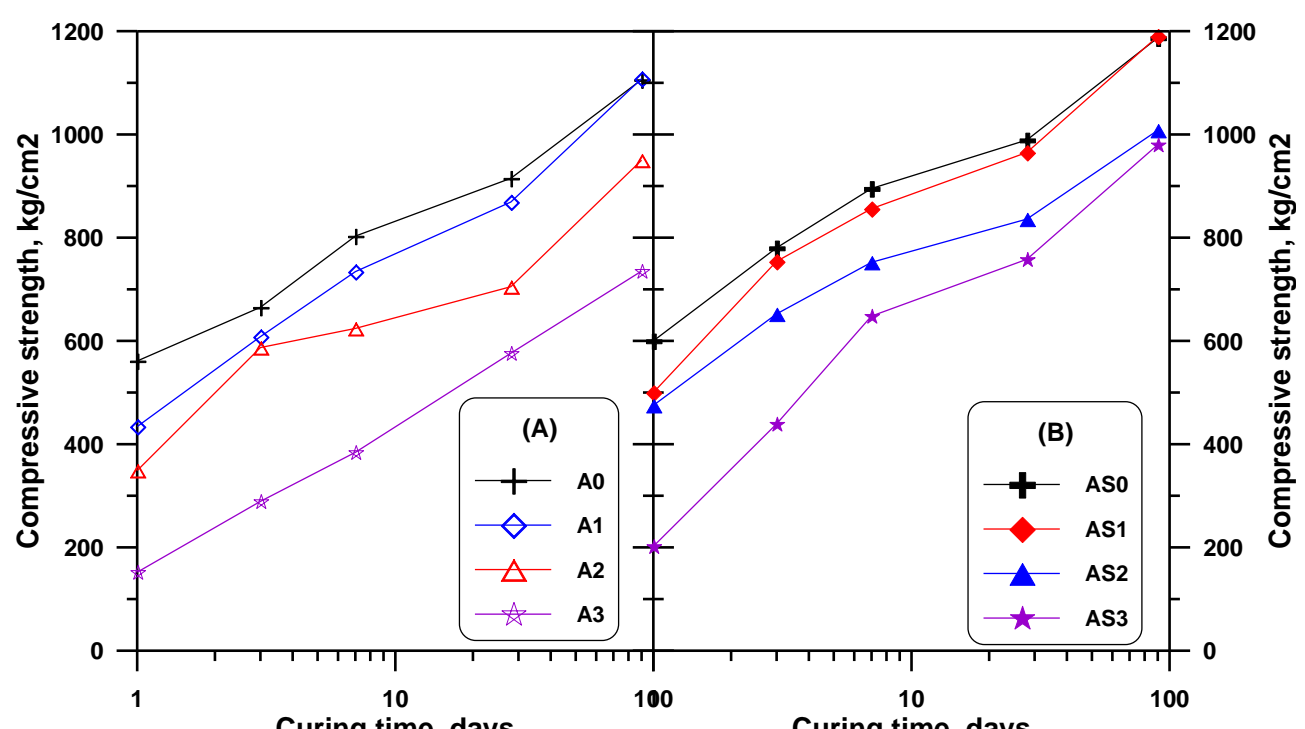

Fig (3) Compressive strength of hydrated OPC and FA-composite cement pastes in the presence andabsence ofsuperplasticizer cured up to 90 days 
M.Heikal, A.I. Ali1, M.N. Ismail, B.S. Ibrahim
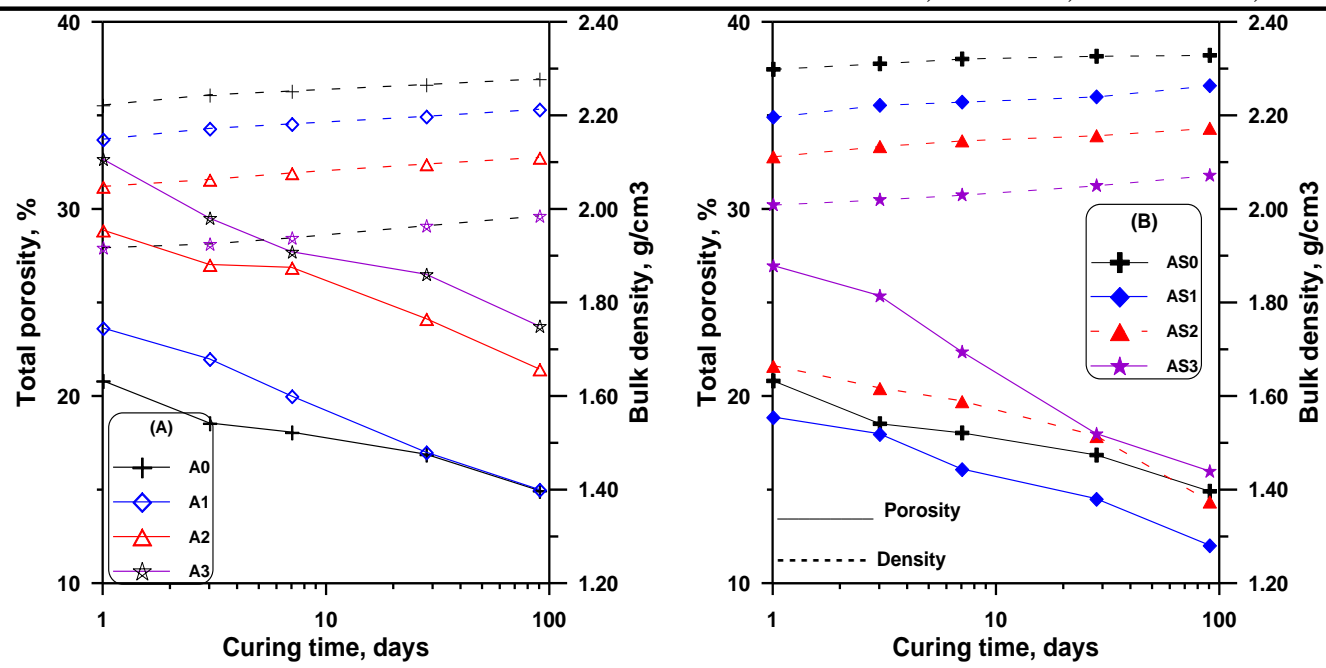

Fig (4) Total porosity and bulk density of hydrated OPC and FA-composite cement pastes in the presence andabsence ofsuperplasticizer cured up to 90 days

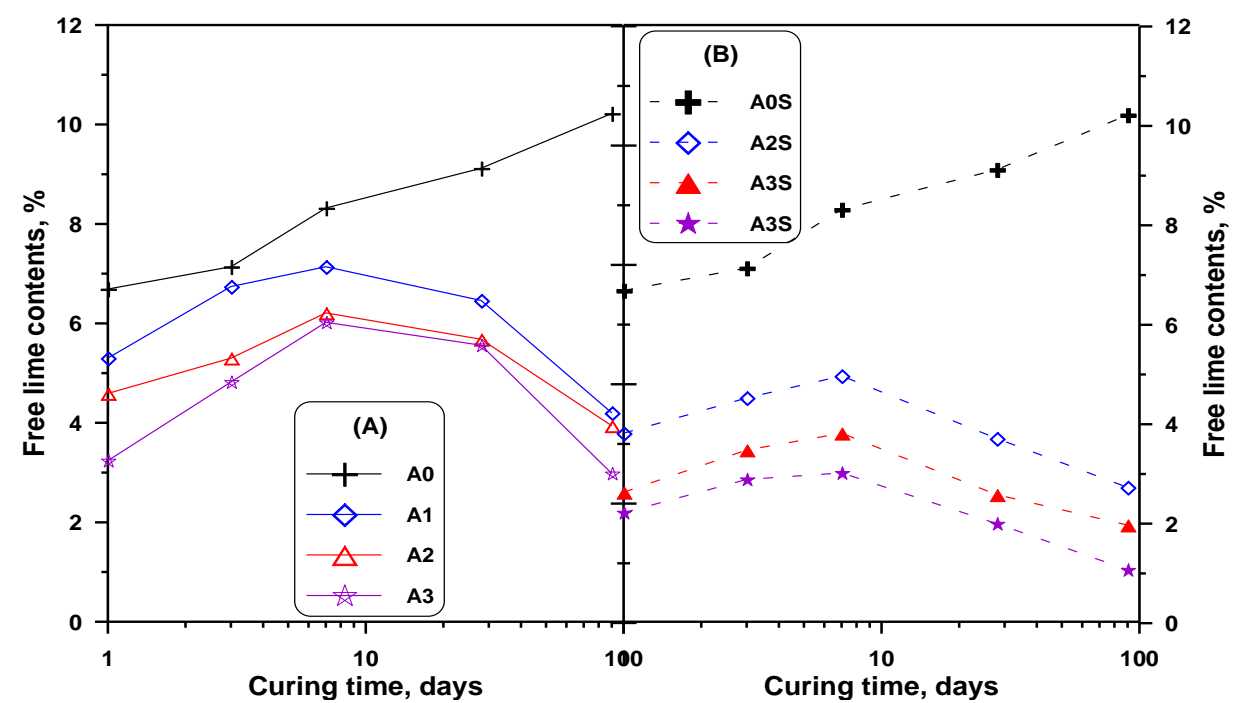

Fig (5) Free lime contents of hydrated OPC and FA-composite cement pastes in the presence and absence of superplasticizer as a function of curing time

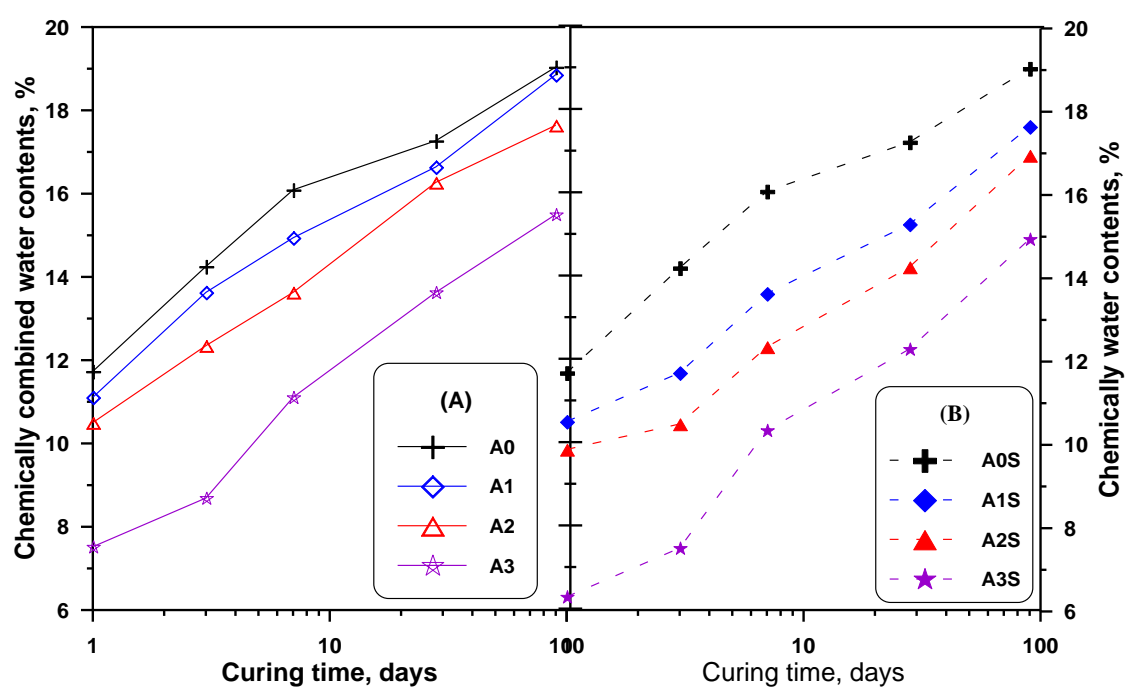

Fig (6) Chemically combined water contents of hydrated OPC and FA-composite cement pastes in the presence and absence of superplasticizer as a function of curing time 


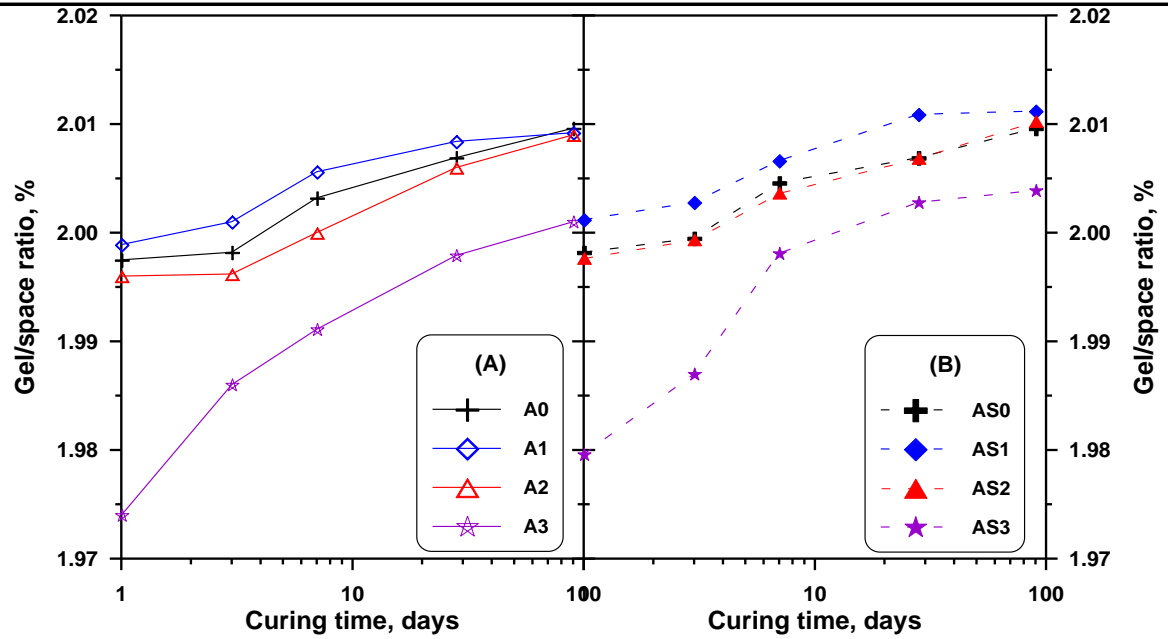

Fig (7) Gel/space ratios of hydrated OPC and FA-composite cement pastes in the presence and absence of superplasticizer as a function of curing time up to 90 days

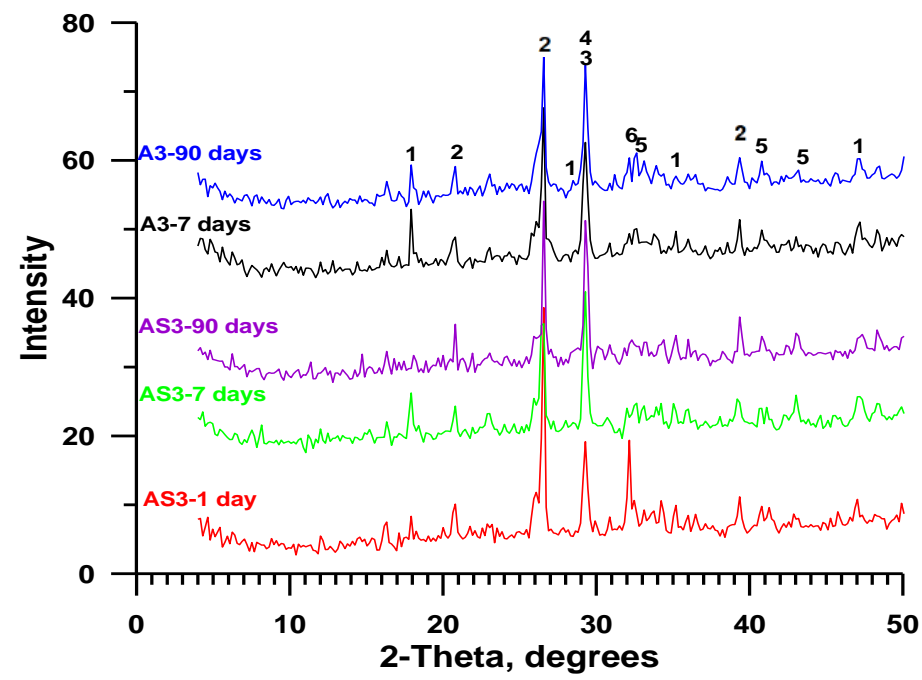

Fig (8) XRD patterns of hardened FA-CCP pastescontaining 50\% FA cured up to 90 days in the presence and absence ofSP; $1=\mathrm{CH} ; 2=$ Quartz; 3 $=\mathrm{C}-\mathrm{S}-\mathrm{H} ; 4=\boldsymbol{C} \overline{\boldsymbol{C}} ; 5=\beta-\mathrm{C}_{2} \mathrm{~S} ; 6=\mathrm{C}_{3} \mathrm{~S}$

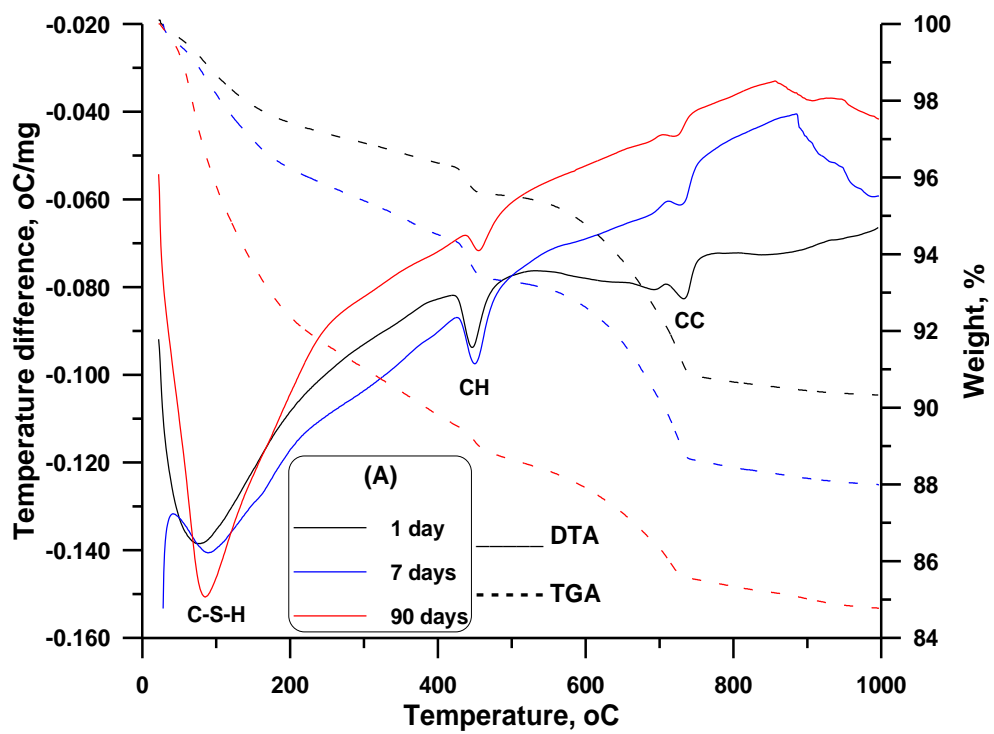

Fig (9A) DTA/TGA thermograms of mix A3 cured at 1, 7 and 90 days 


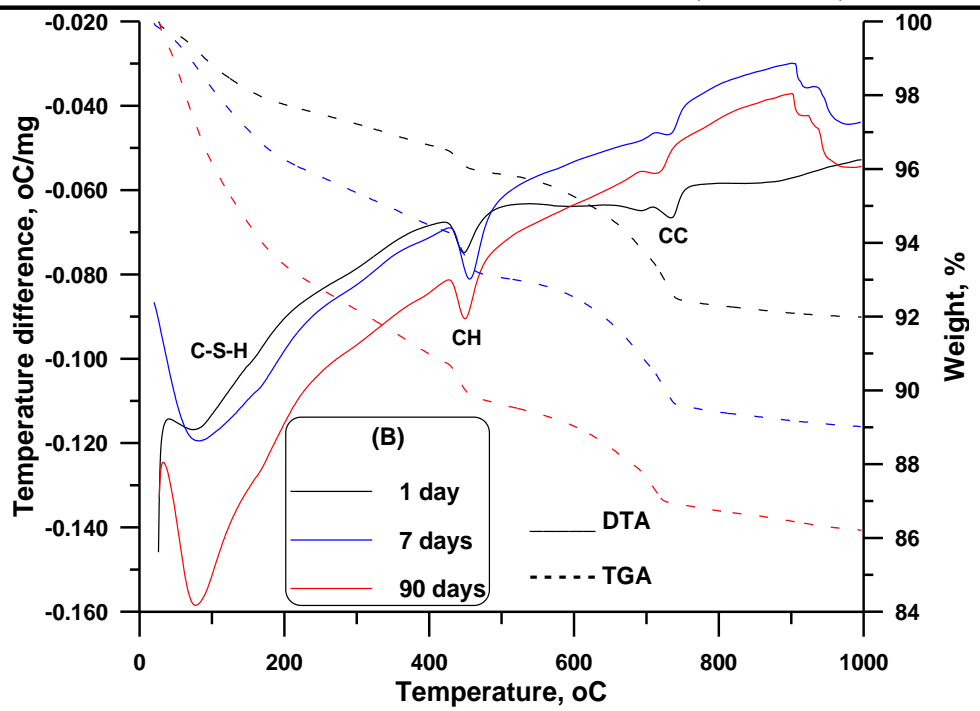

Fig (9B) DTA/TGA thermograms of mix AS3 cured at 1, 7 and 90 days

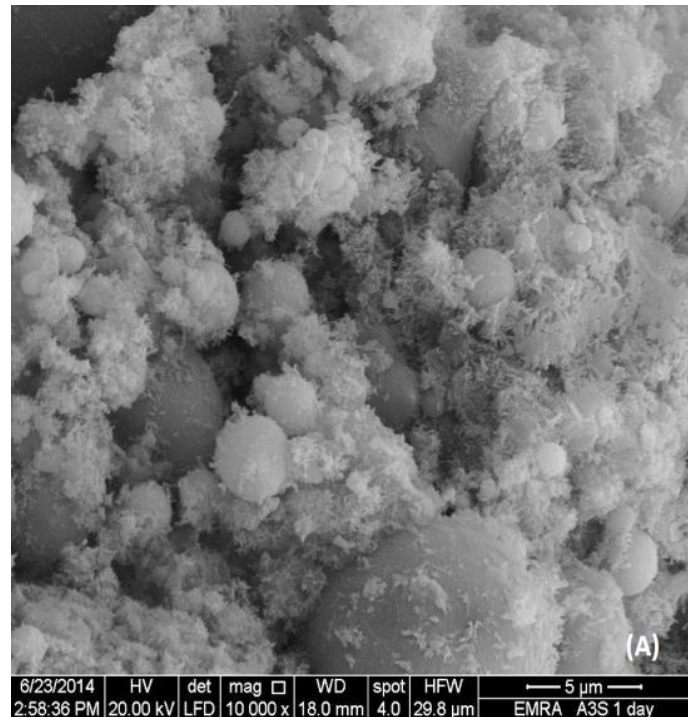

Fig (10) SEM of superplasticizered AS3 mix cured for 1 and 90 days

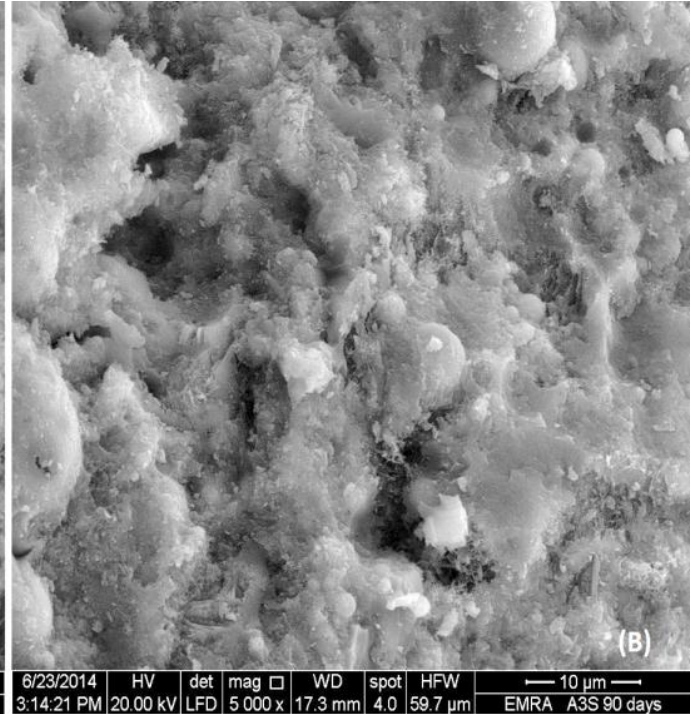

show a lower free lime values than those of specimens without superplasticizer up to 90 days.

5- The increase of FA content decreases the chemically combined water contents.

6- The gel/space ratios of A1 and AS1 mixes show an increase than those of OPC and other FA-CCP pastes in the absence and presence of polycarboxylate SP.

7- The losses of endothermic peak below $200^{\circ} \mathrm{C}$ were found to be $3.09,4.89$ and $8.45 \%$ for $\mathrm{A} 3$ mix, while for AS3 mix were 2.67, 4.57 and 7.30 for specimens hydrated for 1,7 and 90 days respectively, which corresponding to the decomposition of C-S-H, C-A-H and C-A-S-H hydrated products.

8- The hydrated products formed mainly fibril $\mathrm{C}-\mathrm{S}$ H. FA particles partially and fully hydrated show a dense microstructure rim of theinner hydrated product at the surface of reacted and unreacted FA particles. 


\section{References}

[1] Xu. Fly ash in concrete, Ed.S.Chandra, Waste materials used in concrete manufacturing, Noyes Publications Westwood, New Jersey, USA, pp.142-183,1997.

[2] L.S.Shondeep, S.Harsh, Mineral Admixtures in Cement and concrete. New Delhi Indian, P.4, 1993.

[3] R.C.Joshi, R.P.Lohtia, Types and Properties of Fly Ash, MACC, PP.118-157, 1993.

[4] R.C.Joshi, O.J.Thomas, Utilization of modified fly ash, report. University of Calgary, Canada, P.36, 1991.

[5] P.K.Kolay, D.N.Singh, Physical, chemical, mineralogical and thermal properties of cenospheres from an ash lagoon. CemConcr Res vol.31,pp.539-542,2001.

[6] F.Yueming, Y.Suhong, W.Zhiyun, Z.Jingyu, Activation of fly ash and its effects on cement properties. CemConcr Res vol.29, pp.46772,1999 .

[7] Caijun Shi. Early microstructure development of activated lime-fly ash pastes. CemConcr Res vol.26, pp.1351-1359, 1996.

[8] Leshchinsky M, Yu. On fly ash application in concretes. BetonZhelezobeton, 1987;10,144-148.

[9] M.Leshchinsky, A.Leshchinsky, Fly-ash: a poly functional ingredient of concrete. IL Cemento , vol.2, pp.103-112, 1990.

[10] G. Baert, S.Hoste, G.D.Schutter, N.D.Belie, Reactivity of fly ash in cement paste studied by means of thermogravimetry and isothermal calorimetry, J. Therm. Anal. Calorim. Vol.94 ,pp.485-492,2008.

[11] M.Heikal, H.El-Didamony, I.M.Helmy, F.Abd El-Raoof, Pozzolanic activity of fly ash. SiliInd, vol.68,pp.9-10,111-117, 2003.

[12] M.Heikal, H.El-Didamony, I.M.Helmy, F.Abd El-Raoof, Hydration characteristics of fly ashlime pastes. J Mater Sci\& Technolog, vol.12, pp.395-403, 2004.

[13] M.Heikal, H.El-Didamony, I.M.Helmy, F.Abd El-Raoof, Electrical conductivity, physicochemical and mechanical characteristics of fly ash pozzolanic cement. SiliInd vol.69, pp.11-12, 93-102, 2004.

[14] M.Heikal, H.El-Didamony, I.M.Helmy, F.Abd El-Raoof, Electrical properties, physicochemical and mechanical characteristics of fly ash-limestone-filled pozzolanic cement. Ceramics-Silicáty, vol.48,(1), pp.34-43, 2004.

[15] M.A.Abd-El.Aziz, M.Heikal, Hydration characteristics and durability of cements containing fly ash and limestone subjected to Caron's Lake water. AdvCem Res vol.21(3), pp.91-99, 2009.

[16] ASTM Designation: C191, Standard method for normal consistencyand setting of hydraulic cement, ASTM Annual Book of ASTMStandards, 2008.
[17]M.A.Abd-El.Aziz, M.Heikal , S.Abd.El.Aleem, Physico-chemical and mechanical characteristics of pozzolanic cement pastes and mortars hydrated at different curing temperatures. Constr Build Mater, vol.26, pp.310-316, 2012.

[18]H.El-Didamony, M.Abd-El.Eziz, S.Abd.El.Aleem, M.Heikal, Hydrationand durability of sulfate resisting and slag cement blends in Qaron'sLake water. CemConcr Res , vol.35, pp.592-1600, 2005.

[19] ASTM C109, Strength test method for compressive strength of hydraulic cement mortars, 2007.

[20] C.L.Hwang, D.H.Shen, The effect of blastfurance slag and fly ashon the hydration of portland cement. CemConcr Res, vol.21, pp.410425, 1991.

[21] H.El-Didamony, M.Heikal, M.M.Shoaib, Homrapozzolanic cement. SiliInd vol.65, pp.3943, 2000.

[22]M.Heikal, I.Aiad, M.M.Shoaib, H.El-Didamony, hysico-chemical characteristics of some polymer cement composites. J.Mater ChemPhy, vol.71, pp.76-83, 2001.

[23] M.W.Grutzeck, D.M.Roy, B.E.Scheetz, Hydration mechanisms of high lime fly ash in Portland cement composites. Mater Res Soc, vol.102, pp.92-101, 1981.

[24] N.B.Singh, K.W.Bhattacharjee, A.K.Shukla, Hydration of Portland blended cements. CemConcr Res vol.25, pp.1023-1030, 1995.

[25] S.P.Pandey, R.L.Sharma, The Influence of mineral additives on the strength and porosity of OPC mortar, CemConcr Res vol.30, pp.19-23, 2000.

[26] M.I.Khan, C.J.Lynsdale, P.Waldron, Porosity and strength of PFA/SF/OPC ternary blended paste, CemConcr Res , vol.30, pp.1225-1229, 2000.

[27] P.K.Mehta, Properties of Portland cement concrete containing fly ash and condensed silicafume. CemConcr Res, vol.12,(5), pp.587-595, 1982.

[28] S.A.Abo-El-Enein, G.El-kady, T.M.El-Sokkary, M.Gharieb, Physico-mechanical properties of composite cement pastes containing silica fume and fly ash.HBRC J 2014.

[29]M.Heikal, H.El-Didamony, M.S.Morsy, Limestone filled pozzolanic cement. CemConcr Res, vol.30, pp.1827-1834, 2000.

[30]H.El-Didamony, I.M.Helmy, A.A.Amer, M.Heikal, Utilization of some Egyptian byproducts in the preparation of blended cements.Zement-Kalk-Gips, vol.48 (4), pp.502507, 1995.

[31] N.B.Singh, K.W.Bhattacharjee, A.K.Shukla, Hydration of Portland blended cements. CemConcr Res, vol.25 (5), pp.1023-1030, 1995.

[32]S.Hanehara, F.Tomosawa, M.Kobayakawa, K.Hwang, Effect of water/powder ratio, mixing 
M.Heikal, A.I. Ali1, M.N. Ismail, B.S. Ibrahim

ratio of fly ash and curing temperature on pozzolanic reaction of fly ash in cement pastes. CemConcr Res, vol.31(1), pp.31-39, 2001.

[33]L.Lam, Y.L.Wong, C.S.Poon, Degree of hydration and gel/space ratio of high volume fly ash/cement systems. CemConcr Res, vol.30, pp.747-756, 2000.

[34]N.B.Singh, S.P.Singh, R.Sarvahi, A.K.Shukla,The effect of coal dust-fly ash mixture on the hydration of Portland cement. IL Cemento, vol.4, pp.231-238, 1993.

[35] A.M.Neville, The properties of concrete. ELBS, 3re Ed., Pitman Books Limited, P.276, 1983.

[36] M.Heikal, Effect of calcium formate as an accelerator on the physico-chemical and mechanical properties of pozzolanic cement pastes. CemConcr Res, vol.34, pp.1051-1056, 2004.

[37]M.Heikal, A.I.Ali, M.N.Ismail, S.A.N.S.Ibrahim, Behavior of composite cement pastes containing silica nano-particles at elevated temperature. Constr Build Mater, vol.70, pp.339-350, 2014.
[38] M.A.Trezza, A.E.Lavat, Analysis of the system $3 \mathrm{CaO} \cdot \mathrm{Al}_{2} \mathrm{O}_{3}-\mathrm{CaSO}_{4} \cdot 2 \mathrm{H}_{2} \mathrm{O}-\mathrm{CaCO}_{3}-\mathrm{H}_{2} \mathrm{O}$ by FTIR spectroscopy. CemConcr Res, vol.31, pp.869872,2001

[39]M.Heikal, M.Y.Nassar, G.El-Sayed, S.M.Ibrahim, Physico-chemical, mechanical, microstructure and durability characteristics of alkali activated Egyptian slag. Constr Build Mater, vol.69, pp.60-72, 2014.

[40] V.S.Ramachandran, R.M.Paroli, J.J.Beaudoin, A.H.Degado, Handbook of thermo-analysis of construction materials, William Andrew Puplishing, Noyes, 2002.

[41] F.Deschner, F.Winnefeld, B.Lothenbach, S.Seufert, P.Schwesig, S.Dittrich, F.GoetzNeunhoeffer, J.Neubauer, Hydration of Portland cement with high replacement by siliceous fly ash. CemConcrRes, vol.42, pp.1389-1400, 2012.

[42] S.A.Rodger, G.W.Groves, The microstructure of tricalcium silicate/pulverized-fuel ash blended cement pastes. AdvCem Res, vol.1, pp.84-91, 1988 . 